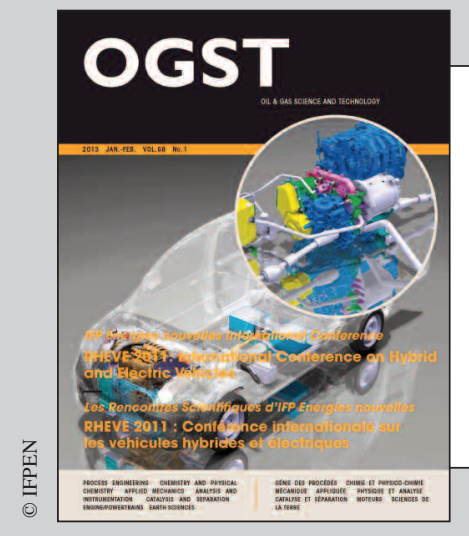

Dossier

This paper is a part of the hereunder thematic dossier published in OGST Journal, Vol. 68, No. 1, pp. 3-178 and available online here

Cet article fait partie du dossier thématique ci-dessous publié dans la revue OGST, Vol. 68, n 1 , pp. 3-178 et téléchargeable ici

DOSSIER Edited by/Sous la direction de : A. Sciarretta, F. Badin et J. Bernard RHEVE 2011 : International Conference on Hybrid and Electric Vehicles RHEVE 2011 : Conférence internationale sur les véhicules hybrides et électriques

Oil \& Gas Science and Technology - Rev. IFP Energies nouvelles, Vol. 68 (2013), No. 1, pp. 3-178

Copyright (C) 2013, IFP Energies nouvelles

\section{$3>$ Editorial}

$13>$ Analysis and Experimental Implementation of a Heuristic Strategy for Onboard Energy Management of a Hybrid Solar Vehicle

Analyse et expérimentation d'une stratégie heuristique pour la gestion d'énergie à bord d'un véhicule hybride solaire

G. Coraggio, C. Pisanti, G. Rizzo and M. Sorrentino

23 > Open Issues in Supervisory Control of Hybrid Electric Vehicles: A Unified Approach Using Optimal Control Methods

Questions ouvertes sur la supervision énergétique des véhicules hybrides électriques : une approche unifiée par la théorie de la commande optimale

L. Serrao, A. Sciarretta, 0. Grondin, A. Chasse, Y. Creff, D. Di Domenico, P. Pognant-Gros, C. Querel and L. Thibault

35 > Optimization of Hybrid Power Trains by Mechanistic System Simulations

Optimisation de groupes motopropulseurs électriques hybrides par simulation du système mécanique

T. Katrašnik and J.C. Wurzenberger

51 > A Phenomenological Heat Transfer Model of SI Engines - Application to the Simulation of a Full-Hybrid Vehicle

Un modèle phénoménologique de transfert thermique au sein de moteurs à allumage commandé - Application à la simulation d'un véhicule full-hybride

R. Dubouil, J.-F. Hetet and A. Maiboom

$65>$ Battery Electric Vehicle (BEV) or Range Extended Electric Vehicle (REEV)? - Deciding Between Different Alternative Drives Based on Measured Individual Operational Profiles

Véhicule électrique à batteries (BEV) ou véhicule électrique à prolongateur d'autonomie (REEV) ? - Choisir entre différents entrânements alternatifs sur la base de profils opérationnels individuels mesurés

S. Marker, B. Rippel, P. Waldowski, A. Schulz and V. Schindler

$79>$ Assessment by Simulation of Benefi ts of New HEV Powertrain Configurations

Évaluation par simulation des bénéfi ces de nouvelles chaînes de traction hybrides

N. Kim and A. Rousseau
95 > Dual Mode Vehicle with In-Wheel Motor: Regenerative Braking Optimization

Véhicule bi-mode avec moteurs roues : optimisation du freinage récupératif

G. Le Solliec, A. Chasse, J. Van-Frank and D. Walser

109 > Engine Downsizing and Electric Hybridization Under Consideration of Cost and Drivability

Réduction de taille moteur et hybridation électrique avec considérations de coût et de performance de conduite

S. Ebbesen, P. Elbert and L. Guzzella

117 > Representative Midwestern US Cycles: Synthesis and Applications Cycles représentatifs du Middle West américain : synthèse et applications

T.-K. Lee and Z.S. Filipi

127 > A Review of Approaches for the Design of Li-lon BMS Estimation Functions

Revue de différentes approches pour l'estimation de l'état de charge de batteries Li-ion

D. Di Domenico, Y. Creff, E. Prada, P. Duchêne, J. Bernard and V. Sauvant-Moynot

137 > Experimental Assessment of Battery Cycle Life Within the SIMSTOCK Research Program

Évaluation expérimentale de la durée de vie de la batterie dans le programme de recherche SIMSTOCK

P. Gyan, P. Aubret, J. Hafsaoui, F. Sellier, S. Bourlot, S. Zinola and F. Badin

$149>$ Smart Battery Thermal Management for PHEV Efficiency Une gestion avancée de la thermique de la batterie basse tension de traction pour optimiser l'efficacité d'un véhicule hybride électrique rechargeable

L. Lefebvre

$165>$ Parameterization and Observability Analysis of Scalable Battery Clusters for Onboard Thermal Management

Paramétrage et analyse d'observabilité de clusters de batteries de taille variable pour une gestion thermique embarquée

Xinfan Lin, Huan Fu, Hector E. Perez, Jason B. Siege, Anna G. Stefanopoulou, Yi Ding and Matthew P. Castanier 


\title{
Open Issues in Supervisory Control of Hybrid Electric Vehicles: A Unified Approach Using Optimal Control Methods
}

\author{
L. Serrao ${ }^{1 *}$, A. Sciarretta ${ }^{1}$, O. Grondin ${ }^{1}$, A. Chasse ${ }^{1}$, Y. Creff 2 , D. Di Domenico², \\ P. Pognant-Gros ${ }^{2}$, C. Querel ${ }^{1}$ and L. Thibault ${ }^{1}$ \\ 1 IFP Energies nouvelles, 1-4 avenue de Bois-Préau, 92852 Rueil-Malmaison Cedex - France \\ 2 IFP Energies nouvelles, Rond-point de l'échangeur de Solaize, BP 3, 69360 Solaize - France \\ e-mail: lorenzo.serrao@dana.com - antonio.sciarretta@ifpen.fr - olivier.grondin@ifpen.fr - alexandre.chasse@ifpen.fr \\ yann.creff@ifpen.fr - domenico.di-domenico@ifpen.fr - philippe.pognant-gros@ifpen.fr - carole.querel@ifpen.fr \\ laurent.thibault @ifpen.fr \\ *Corresponding author, now with Dana Corp., Arco - Italy
}

\begin{abstract}
Résumé - Questions ouvertes sur la supervision énergétique des véhicules hybrides électriques : une approche unifiée par la théorie de la commande optimale - Cet article a pour objet la gestion optimale de l'énergie pour un système de propulsion hybride. Le problème traditionnel de répartition de la puissance est modifié avec des nouveaux objectifs d'optimisation et des nouvelles contraintes. Les nouveaux objectifs d'optimisation incluent les émissions de polluants et le vieillissement de la batterie. Les contraintes sont modifiées pour prendre en compte des batteries à recharge externe (hybrides plug-in). De plus, des problèmes spécifiques sont traités avec une modélisation plus détaillée, qui comprend : les dynamiques thermiques du moteur à combustion interne et du catalyseur, pour prendre en compte les effets du démarrage à froid; les dynamiques thermiques des systèmes de récupération de la chaleur à l'échappement; la température de la batterie, qui a un effet sur ses performances et son vieillissement. L'article montre comment tous ces problèmes peuvent être traités de façon cohérente avec une extension de l'approche ECMS (Equivalent Consumption Minimization Strategy, ou stratégie de minimisation de la consommation équivalente), qui est une implémentation du principe du minimum de Pontryagin formulé dans la théorie de la commande optimale. Des définitions étendues de la fonction Hamiltonienne et des multiplicateurs de Lagrange sont présentées, ainsi que les résultats des optimisations illustrant les bénéfices de cette approche unifiée et ses limites dans l'implémentation en ligne.
\end{abstract}

\begin{abstract}
Open Issues in Supervisory Control of Hybrid Electric Vehicles: A Unified Approach Using Optimal Control Methods - Energy management of hybrid propulsion systems is considered, presenting new issues that extend the energy management role beyond the standard torque splitting to maximize system efficiency. The new issues include additional optimization criteria, constraints and relevant dynamics to deal with. New optimization criteria in addition the sole fuel consumption minimization include engine-out pollutant emissions and battery aging. State constraints are modified to account for plug-in hybrid vehicles. Moreover, specific supervisory control problems are recognized to need additional state variables. The latter comprise: engine and catalyst temperature to deal with engine warm-up effects on fuel consumption and after-catalyst emissions; thermal dynamics of heat recovery systems (Rankine or Thermo-Electric Generators, TEGs); and battery temperature, which influences battery performance and aging. It is shown that all these control problems can be treated in an unified fashion by extending the well-known ECMS (Equivalent Consumption Minimization
\end{abstract}


Strategy), which is an implementation of Pontryagin Minimum Principle (PMP) as formulated by optimal control theory. Extended definitions of the Hamiltonian function and Lagrange multipliers are introduced. Optimization runs performed off line are reported. Results show the benefits of the proposed unified approach and enlighten some first online implementation issues.

\section{INTRODUCTION}

It is well known that hybrid electric vehicles (HEV) may be significantly more efficient than conventional (engine-only) vehicles. This is due in part to their capability of recovering braking energy and in part to the additional degree of freedom due to the presence of two energy sources on board of the vehicle (electrical energy storage and fuel tank). The presence of this additional degree of freedom introduces the necessity of an appropriate energy management strategy in order to exploit it effectively. Many methods have been proposed to design an energy management strategy (see the overview in [1]), including heuristic strategies, numerical optimization methods and optimal control theory. In particular, thanks to some specific properties of the HEV problem, it is possible to easily implement solutions based on optimal control theory. The most well known case is the Equivalent Consumption Minimization Strategy (ECMS), based on Pontryagin's Minimum Principle (PMP) [2-5]. Most of the work related to ECMS focuses on its basic application, i.e. minimizing fuel consumption using a simple, quasi-static vehicle model. The objective of this paper is to provide an overview of the current research activities aimed at expanding the range of use of the ECMS approach, either by targeting multiple optimization objectives or by improving the modeling detail. The basic theory is recalled in Section 1, then several cases are examined in the following sections, starting with the standard formulation in Section 2 and then adapting the problem formulation to a specific goal.

\section{MINIMUM PRINCIPLE FOR A GENERAL OPTIMAL CONTROL PROBLEM}

Consider a system described by the generic state equation:

$$
\dot{x}=f(x, u, t)
$$

where $x$ is the state vector, $u$ the control vector, $t$ the time. Consider the optimal control problem of finding the sequence of controls $u^{*}(t)$ that minimizes the cost function:

$$
J=\int_{0}^{t_{f}} L(x, u, t) d t
$$

subject to control and state constraints, as well as prescribed initial conditions on the system state.

Define the Hamiltonian function as:

$$
H(x, u, t)=L(x, u, t)+\lambda^{T}(t) \cdot f(x, u, t)
$$

where $\lambda(t)$ is the problem co-state vector (with same dimension as the state vector). Pontryagin's minimum principle states that the optimal solution $u^{*}(t)$ is such that the following conditions are satisfied:

- at each time, the optimal solution of the global problem is also the solution to the instantaneous problem of minimizing the Hamiltonian function, i.e.:

$$
u^{*}(t)=\arg \min _{u}(H(x, u, t))
$$

- the co-state variable appearing in the Hamiltonian function evolves according to the Euler-Lagrange equation:

$$
\dot{\lambda}(t)=-\frac{\partial H}{\partial x}=-\frac{\partial L(x, u, t)}{\partial x}-\lambda^{T}(t) \frac{\partial f(x, u, t)}{\partial x}
$$

Equations (4) and (5) provide the solution to the problem, under the hypothesis that the optimal control $u^{*}(t)$ exists and is unique ${ }^{(1)}$.

\section{STANDARD PMP AND ECMS}

\subsection{Problem Formulation}

In this section, the generic optimal control problem introduced in Section 1 is explicitly written for a hybrid electric vehicle, using the standard formalization in literature (see e.g. [1] or [5]). Assuming a vehicle that follows a prescribed driving cycle and neglecting all fast dynamics in the powertrain as well as the thermal phenomena, the vehicle state can be represented by the battery State of Charge (SOC) $\xi$, that is: $x=\{\xi\}$. The system dynamic equation $f(x, u, t)$ is then:

$$
\dot{\xi}(\xi, u, t)=-\frac{1}{Q_{b}} I_{b}(\xi, u, t)
$$

where $I_{b}$ is the battery current and $Q_{b}$ the battery charge capacity.

The control variable is generically indicated as $u(t)$ and represents the power split between the on board energy sources.

In the standard case, in which fuel consumption minimization is the only optimization objective, the instantaneous cost $L(x, u, t)$ is the fuel flow rate, expressed in terms of fuel power (which does not depend explicitly on SOC):

$$
L(\cdot)=P_{f u e l}(u, t)=Q_{l h v} \dot{m}_{f}(u, t)
$$

( $Q_{l h v}$ being the constant fuel energy density). In the following sections, cases in which $L(\cdot)$ takes different meanings are also considered.

(1) The existence and uniqueness of the solution have not been proved in the general case but are generally accepted conditions in the typical HEV case, for which Kim et al. [6] provided a formal proof under some mildly simplifying hypotheses (constant co-state). 
The optimization problem is extended to the time interval $\left[0, t_{f}\right]$ and consists in finding the optimal control $u^{*}(t)$ that minimizes the total cost:

$$
J=\int_{0}^{t_{f}} L(\xi, u, t) d t
$$

subject to the following constraints:

- initial conditions and system dynamics:

$$
\begin{gathered}
\xi(0)=\xi_{0} \\
\xi(t)=f(\xi, u, t)
\end{gathered}
$$

- instantaneous constraints:

$$
\begin{gathered}
u_{\min }(t) \leq u(t) \leq u_{\max }(t) \quad \forall t \in\left[0, t_{f}\right] \\
\xi_{\text {min }} \leq x(t) \leq \xi_{\text {max }} \quad \forall t \in\left[0, t_{f}\right]
\end{gathered}
$$

- global constraints:

$$
\xi\left(t_{f}\right)=\xi_{f}
$$

Equation (13) represents a generally accepted terminal condition, which imposes a pre-defined final battery SOC (typically the same as the initial value, for charge-sustaining HEV). However, its use is justified mainly as a way to compare the results of different solutions by guaranteeing that they reach the same level of battery energy. In real vehicles, there is no need to have a fixed battery SOC at the end of each cycle but only to keep it always between two boundary values as defined by (12).

\subsection{Optimal Control Solution}

The Hamiltonian is:

$$
H(\xi, u, t)=P_{f u e l}(u, t)-\lambda(t) \cdot \frac{1}{Q_{b}} I_{b}(\xi, u, t)
$$

Let us write the co-state $\lambda(t)$ as the product of the battery total energy (constant) and a non-dimensional factor $s(t)$ :

$$
\lambda(t)=-E_{b} \cdot s(t)=-V_{o c, \max } Q_{b} s(t)
$$

where $E_{b}=V_{o c, \max } Q_{b}$ is the battery total energy content, product of the open circuit voltage $V_{o c}$ and charge capacity $Q_{b}$. The non-dimensional term $s(t)$ is called equivalence factor.

When $\lambda$ is replaced with this expression, the Hamiltonian function can be interpreted as an equivalent fuel consumption (or more precisely, an equivalent fuel power):

$$
H(\xi, u, t)=P_{f u e l}(u, t)+s(t) \cdot P_{e c h}(\xi, u, t)
$$

where $s(t)$ can be interpreted as a weighting factor of the battery power consumption with respect to the fuel power. $P_{e c h}(\xi, u, t)=V_{o c, \text { max }} I_{b}(\xi, u, t)$ is the electrochemical power, i.e. the power that corresponds to the effective battery discharge $^{(2)}$.

Since it is proportional to $\lambda(t)$, the equivalence factor evolves in time according to Equation (5), i.e.:

$$
\dot{s}(t)=-\frac{\partial P_{f u e l}(u, t)}{\partial \xi}-s(t) \frac{\partial P_{e c h}(\xi, u, t)}{\partial \xi}
$$

The first term of Equation (17) is zero (the fuel consumption does not depend directly on SOC) and in most cases, the second term is also approximated to zero, neglecting the SOC effect on the effective charge/discharge power, i.e. assuming that the battery parameters (e.g. internal resistance) do not depend sensibly on state of charge ${ }^{(3)}$. Under this simplification, $s(t)$ is approximately constant, which allows to prove the existence and uniqueness of the optimal solution [6] and also to simplify the online implementation.

The boundary conditions of the problem are given in terms of the initial and final value of the system state, while the co-state is completely free. For the numerical solution, the so called shooting method is used to deal with the split boundary conditions: the method consists in applying an iterative search procedure to find the initial value of the co-state, $s(0)$, that generates the desired final value of the state (13).

The shooting method procedure requires several runs of the same driving cycle, which is obviously possible only for off line optimization. Instead, for online implementation, it is assumed that the variation due to Equation (17) is negligible, and that there exists an optimal constant value of $s$ that brings the SOC to a desired final value $\xi_{\text {ref }}$. Since this optimal value is unknown a priori, the value of $s(t)$ at each instant is computed by correcting the initial guess $s_{0}$ with a term proportional to the difference between the measured SOC value and its reference value $\xi_{\text {ref }}$. In other words, $s(t)$ is corrected with a feedback on the system state, in order to reach the reference value at steady state. The feedback law takes the form of a PI-controller [7-9]:

$$
s(\xi, t)=s_{0}+k_{P}\left(\xi_{r e f}-\xi(t)\right)+k_{I} \int_{0}^{t}\left(\xi_{r e f}-\xi(\tau)\right) d \tau
$$

Other online adaptation methods were also devised, including methods based on driving cycle prediction [10], on driving pattern recognition [11] or SOC-feedback based on driving cycle sections [12]. The off line implementation is normally referred to as PMP, while the online implementation is denoted as ECMS (Equivalent Consumption Minimization Strategy), or sometimes adaptive ECMS to

(2) The effective battery discharge is different than the net electrical energy supplied by the battery, because of the battery efficiency, which makes the electrochemical power higher than the electric power during discharge and lower during charge.

(3) This simplification is a good approximation in most cases, especially if the battery is maintained in a relatively narrow range of SOC. 
point out the fact that the equivalence factor is dynamically adapted to the actual driving conditions.

\subsection{Limits and Extension of the Standard ECMS Formulation}

The standard ECMS formulation provides very good results within the limits of its hypotheses. In fact, if PMP with appropriately tuned equivalence factor can be identical to the numerical optimum computed with dynamic programming, thanks to the fact that both provide the optimal solution [5], the online ECMS implementation with adaptation of $s(t)$ based on SOC-feedback can be very close to the optimal solution (within 1-2\% in terms of total cost) [7].

However, in some cases, the hypotheses on which the standard ECMS is based (quasi-static, iso-thermal behavior) may be unrealistic and therefore, the solution provided is not actually optimal. This is particularly true for the temperature variation, as shown in Section 6.1.

In addition to this, in some cases the optimization objectives can be more complex than simple fuel consumption minimization: for example, there may be additional terms in the cost function, such as pollutant emissions, battery aging; or additional constraints, for special applications (e.g. plugin HEV); or the need to perform a three-way power split if there are more energy sources on board.

In the following sections, modifications to the standard ECMS, in various forms, are proposed. All are based on previously published works, showing that they can all be cast into a unified framework. The definition of the problem in the appropriate form is only the first step; the solution of the problems presented in the following sections still presents many open issues, currently object of active research.

\section{MODIFICATIONS TO BOUNDARY CONDITIONS}

\subsection{Battery Depletion for Plug-in Vehicles}

In plug-in hybrid electric vehicles, the objective is not to maintain the battery SOC around its nominal value, as in standard HEVs, but rather to discharge the battery as much as possible before plugging the vehicle in the electric grid, in order to minimize the use of fuel and maximize the use of electrical energy $[13,14]$.

\subsubsection{Problem Definition}

The problem formulation given in Section 2.1 remains formally identical. However, the final value of the battery SOC is different than the initial one, i.e. $\xi_{f} \neq \xi_{0}$.

\subsubsection{Solution}

The new final condition does not change the off-line optimization with respect to the standard case: the optimal value of $s(0)$ will still correspond to the specified final value. However, there is some variation in the online implementation: the reference value $\xi_{\text {ref }}$ appearing in Equation (18) is not constant anymore but it changes during the driving cycle. Unless offline optimization is carried out beforehand, the reference value is not actually known a priori; therefore, it must be approximated: one possible method [14] consists in assuming a nominal discharge profile, for example evolving linearly with the distance (blended mode). An alternative solution is to discharge completely the battery initially, then regulate around a low-SOC constant reference level (charge depleting/charge sustaining mode or CD/CS).

\section{Blended mode}

This mode consists in applying Equation (18) during the entire cycle, with $\xi_{\text {ref }}$ computed at each instant as a function of the distance:

$$
\begin{gathered}
s(\xi, t)=s_{0}+k_{P}\left(\xi_{r e f}(t)-\xi(t)\right)+k_{I} \int_{0}^{t}\left(\xi_{r e f}(\tau)-\xi(\tau)\right) d \tau \\
\xi_{r e f}(t)=\xi(0)-\frac{D(t)}{D_{t o t}} \cdot\left(\xi(0)-\xi_{f}\right)
\end{gathered}
$$

with $D(t)$ being the current distance traveled, $D_{t o t}$ the total distance before reaching a recharge point, $\xi_{f}$ the target final state of charge (low level, from which to recharge). Obviously, this method requires preliminary knowledge or estimation of the total distance $D_{t o t}$, for example by using the route planned by a GPS device; the linearity of the discharge profile with the distance is only an approximation of the assumed optimal behavior.

\section{CD/CS mode}

The second case corresponds to the introduction of a discontinuity in the value of $s$, which is zero in the first part of the cycle (tendency to discharge as much as possible, i.e. to minimize fuel consumption without weighting the battery discharge), while in the second part of the cycle - once the SOC has decreased below a threshold value - it takes the value given by Equation (18), with $\xi_{\text {ref }}$ constant, in order to keep the solution charge-sustaining.

\subsubsection{Results}

Figure 1 shows an example of a plug-in HEV with the two strategies thus far outlined. The example is taken from simulations of a heavy-duty series HEV, currently being developed by IFP Energies nouvelles and industrial partners, and shows that the blended mode is more efficient than the $\mathrm{CD} / \mathrm{CS}$ mode, as it is expected since it represents the direct implementation of PMP for the entire cycle, while the $\mathrm{CD} / \mathrm{CS}$ mode corresponds to splitting the problem in two sections, each with different boundary conditions. On the other hand, online implementation of blended mode is only possible if the total trip distance is known in advance, which is not normally the case. The results in Figure 1 show a relatively small difference between the blended mode and the 

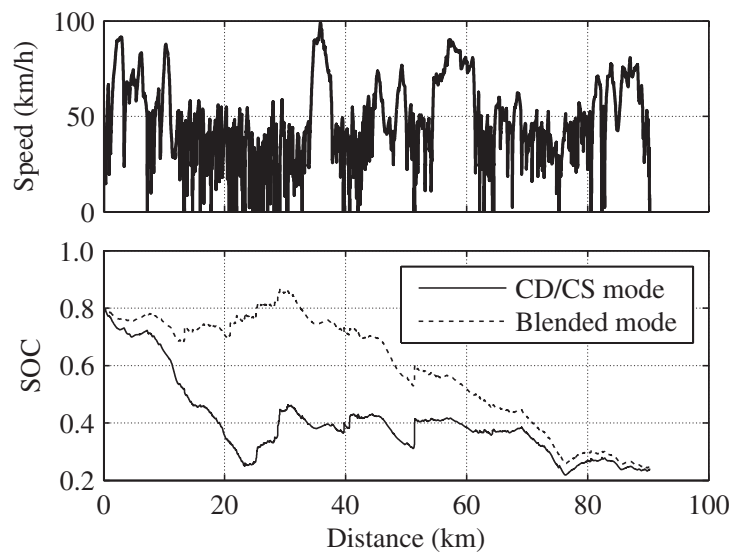

Figure 1

Charge-depleting (plug-in) HEV: comparison between blended-mode and CD/CS mode, for a heavy-duty series HEV. Fuel consumption in blended mode is $2.5 \%$ better than in $\mathrm{CD} / \mathrm{CS}$ mode.

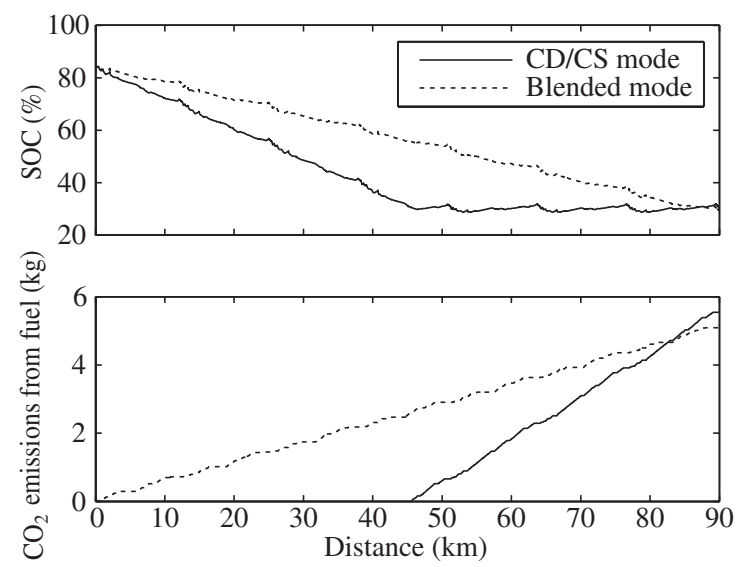

Figure 2

Charge-depleting (plug-in) HEV: comparison between blended-mode and CD/CS mode, for the $G M$ Volt powertrain, over a 90-km trip (repet. of US06 cycle). In this case, blended mode results in a fuel consumption reduction of $8 \%$ with respect to $\mathrm{CD} / \mathrm{CS}$ mode [15].

$\mathrm{CD} / \mathrm{CS}$ mode (fuel consumption in blended mode is $2.5 \%$ smaller than it is in $\mathrm{CD} / \mathrm{CS}$ mode). This is most likely due to the fact that the case study is a series HEV, with a heavy-duty Diesel engine: the relatively flat efficiency characteristic of the engine translates into low potential for optimization, thus the differences between the strategies are fairly small. Another example of plug-in HEV, for which it is easier to see the advantage of blended mode, is the Chevrolet Volt. Results of simulations realized with the Hybrid Optimization Tool (HOT) developed at IFP Energies nouvelles $[2,7]$ and based on $G M$ published data [15-17] are reported in Figure 2: the fuel consumption reduction with the blended mode in this case is in the order of $8 \%$, showing the high potential for improvement if trip length before recharge is known in advance.

\section{MODIFICATIONS TO COST FUNCTION}

In the standard case described in Section 2, the optimization criterion applied is the overall fuel consumption. However, different objectives can be defined: for example, the amount of pollutant emissions, the battery wear and aging or - in the case of plug-in vehicles - the overall economic cost, the total amount of $\mathrm{CO}_{2}$ emissions, etc.

In this section, two cases are presented: minimization of emissions along with fuel consumption and minimization of battery aging, both assuming a charge-sustaining HEV.

\subsection{Pollutant Emissions}

For a Diesel HEV, the optimization criterion can be adapted in order to take into account $\mathrm{NO}_{x}$ emissions $[3,18,19]$. The fuel mass flow rate and the $\mathrm{NO}_{x}$ emission strongly depend on the engine operating condition. As a first approximation, in [19] two static maps depending on engine speed $N_{e}$ and torque $T_{e n g}$ are used to model the emissions:

$$
\begin{gathered}
\dot{m}_{f}(t)=f_{F C}\left(T_{\text {eng }}, N_{e}\right) \\
\dot{m}_{\mathrm{NO}_{x}}(t)=f_{\mathrm{NO}_{x}}\left(T_{\text {eng }}, N_{e}\right)
\end{gathered}
$$

\subsubsection{Problem Definition}

The energy supervisor should provide a compromise between fuel consumption reduction and $\mathrm{NO}_{x}$ emission abatement [19]. In order to do so, the term $P_{\text {fuel }}$ in the cost function (7) is replaced by the sum of fuel consumption and emission rates:

$$
P_{f u e l}^{*}=Q_{l h v}\left[\left(1-\alpha_{1}\right) \dot{m}_{f}+\alpha_{1} \dot{m}_{\mathrm{NO}_{x}}\right]
$$

where the parameter $\alpha_{1}$ is used to set the trade-off between fuel consumption and $\mathrm{NO}_{x}$ emission. Then, the problem formulation consists in the minimization of the cost:

$$
J=\int_{0}^{t_{f}} P_{f u e l}(t) \cdot\left(1-\alpha_{1}\right)+P_{\mathrm{NO}_{x}}(t) \cdot \alpha_{1} d t
$$

where $P_{\mathrm{NO}_{x}}$ is the product of the fuel lower heating value $Q_{l h v}$ and the $\mathrm{NO}_{x}$ emission rate.

\subsubsection{Solution}

Since the cost function is the only difference with respect to the standard case, the Hamiltonian of the problem shows the same structure as (16):

$$
H(t)=P_{f u e l}(t) \cdot\left(1-\alpha_{1}\right)+P_{\mathrm{NO}_{x}}(t) \cdot \alpha_{1}+s(t) \cdot P_{\text {ech }}(t)
$$

The solution is identical to the standard case, since the differences in the cost function do not affect the co-state dynamics (i.e., it is still $s(t) \approx s_{0}$ ). 


\subsubsection{Results}

Simulation results are presented in Figure 3. These simulations are performed with the weighting parameter $\alpha_{1}$ ranging from 0 to 0.65 (i.e. from the minimum of fuel consumption to the minimum of $\mathrm{NO}_{x}$ emission). The trends are clear and demonstrate the great potential for limiting $\mathrm{NO}_{x}$ emission at a price of a very small increase of fuel consumption. The achievable $\mathrm{NO}_{x}$ reduction is close to $40 \%$ for FTP (US Federal Test Procedure) cycle. On the other hand, the fuel penalty is small and does not exceed $5 \%$.
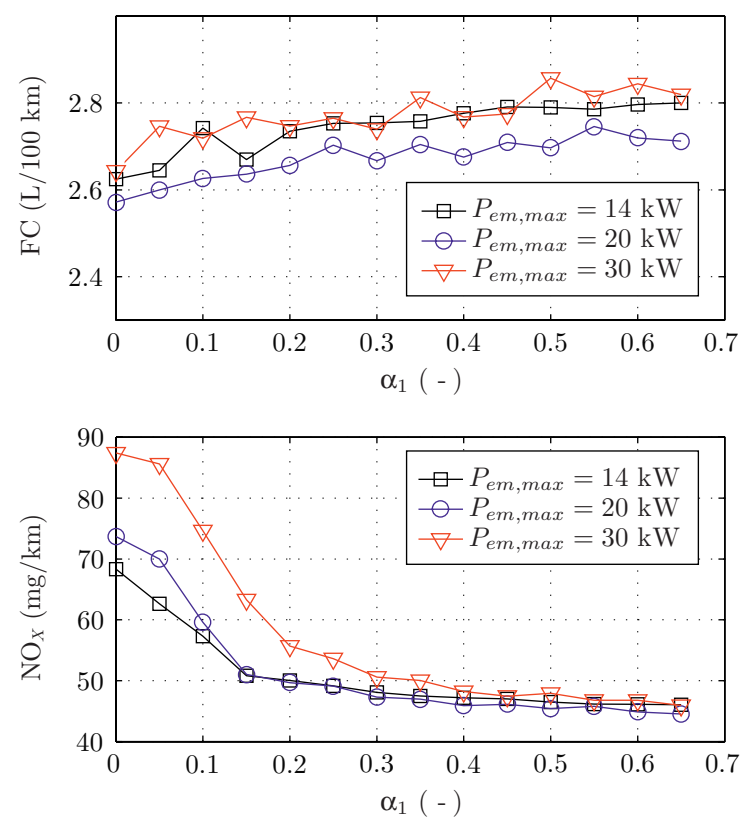

Figure 3

Simulated fuel consumption and $\mathrm{NO}_{x}$ for the FTP cycle as a function of parameter $\alpha_{1}$.

Table 1 and Figure 4 show the experimental results of the proposed strategy. The engine tests where performed on an engine in-the-loop test bench [2]. The considered Diesel engine is a supercharged, 1.6 liters, four cylinder engine fitted with low pressure and high pressure Exhaust Gas Recirculation (EGR) systems. The Diesel engine calibration allows Low-Temperature Combustion (LTC) operation and the engine has no dedicated after-treatment system for $\mathrm{NO}_{x}$ emissions. The bench allows to test several vehicle configurations: conventional vehicle (architecture A), microhybrid electric vehicle with stop and start capability (architecture B) and parallel hybrid HEV (architecture C). The comparison concerns the achitecture $\mathrm{C}$ with a fuel-economy optimization and a $\mathrm{NO}_{x}$ reduction optimization. The test results are summarized in Table 1 and in Figure 4. This confirms the offline simulation results plotted in Figure 3. The parameter $\alpha_{1}$ allows to reduce the $\mathrm{NO}_{x}$ emission at the price of a small increase in fuel consumption. These results confirm the simulated behavior of engine performances and

\section{TABLE 1}

Experimental results from [19]: comparison of powertrain configuration including Fuel Consumption (FC) and $\mathrm{NO}_{x}$ oriented optimization and validation with experimental results (NEDC cycle)

\begin{tabular}{|l|c|c|c|c|}
\hline Vehicle architecture & A & B & C & C \\
\hline Mass $(\mathrm{kg})$ & 1470 & 1470 & 1630 & 1630 \\
\hline Hybrid strategy & - & $\mathrm{SS}$ & $\begin{array}{c}\mathrm{FC} \\
\alpha_{1}=0.2\end{array}$ & $\begin{array}{c}\mathrm{NO}_{x} \\
\alpha_{1}=0.5\end{array}$ \\
\hline FC - experim. $(\mathrm{L} / 100 \mathrm{~km})$ & 4.45 & 4.16 & 3.43 & 3.50 \\
\hline FC - model $(\mathrm{L} / 100 \mathrm{~km})$ & 4.31 & 4.17 & 3.30 & 3.52 \\
\hline $\mathrm{NO}_{x}$ - experim. $(\mathrm{mg} / \mathrm{km})$ & 109 & 100 & 82 & 67 \\
\hline $\mathrm{NO}_{x}$ - model $(\mathrm{mg} / \mathrm{km})$ & 92 & 79 & 68 & 52 \\
\hline
\end{tabular}

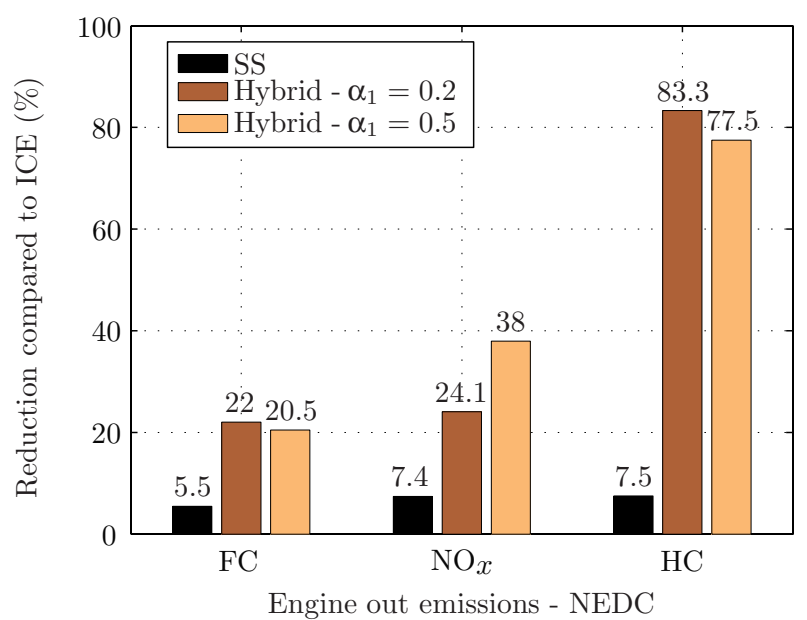

Figure 4

Summary of the experimental results in [19]. The gains are relatives to the stand-alone Diesel engine (architecture A). Three configurations are displayed: vehicle B (with Stop and Start), vehicle $C$ with $\alpha_{1}=0.2$ and vehicle $C$ with $\alpha_{1}=0.5$.

prove that the adapted ECMS is suitable for the Diesel HEV. It should be noticed that the power split behavior is modified compared to the standard optimization policy applied for gasoline HEV. More details can be found in [19].

\subsection{Battery Aging}

Similarly to what happens for the pollutant emissions, it is possible to modify the problem definition to include in the cost function the reduction of battery life during the driving cycle [20]. If the battery temperature variation is neglected (assuming perfect cooling), then the problem can be formulated once again as in the standard case, only modifying the cost function.

\subsubsection{Problem Definition}

The reduction of battery life is proportional to the integral of the current flow in and out of the battery, corrected with 
a severity factor $\sigma$ that determines the aging effect of the instantaneous operating conditions. The instantaneous cost function is therefore:

$$
\begin{aligned}
L(\xi, u, t)= & \left(1-\alpha_{2}\right) Q_{l h v} \dot{m}_{f}(u, t) \\
& +\alpha_{2} c_{a} \frac{\sigma\left(\xi, u, \theta_{b}\right)\left|I_{b}(\xi, u, t)\right|}{\Gamma}
\end{aligned}
$$

where $\Gamma$ is the total battery life in nominal conditions, expressed in Ah (a constant value for a given battery), $\sigma\left(\xi, u, \theta_{b}\right)$ is the severity factor of the instantaneous operating conditions (SOC, current intensity, battery temperature) and $c_{a}$ a cost conversion factor necessary to make dimensionally homogeneous the two terms of the cost. $\alpha_{2}$, on the other hand, is a weighting factor to decide the importance of each term. The temperature is assumed to be constant, to keep the formulation simpler. (This assumption is removed in Sect. 6.3).

\subsubsection{Solution}

The Hamiltonian is:

$$
\begin{aligned}
H(\xi, u, t)= & \left(1-\alpha_{2}\right) P_{f u e l}(u, t) \\
& +\alpha_{2} c_{a} \frac{\sigma\left(\xi, u, \theta_{b}\right)\left|I_{b}(x, u, t)\right|}{\Gamma} \\
& +s(t) \cdot P_{e c h}(\xi, u, t)
\end{aligned}
$$

Since the aging term in instantaneous cost (26) depends directly on the SOC $\xi$, the dynamic variation of $s(t)$ given by Equation (17) cannot be neglected a priori and instead should account for this effect.

\subsubsection{Results}

The simulation results of Figure 5 show the solution to this problem for three values of the weighting factor $\alpha_{2}$, clearly indicating the fact the value of $s$ depends on $\alpha_{2}$, i.e. on the definition of the cost. The term $s(t)$ also appears to be approximately constant in all cases, meaning that the variation due to battery aging and SOC dynamics are both negligible.

Figure 6 provides global results for the same cases, showing the trade-off between fuel consumption and longer battery life, which increases significantly in some cases. In fact, for higher values of $\alpha_{2}$, the battery is used at lower power to preserve its life, but this obviously reduces the HEV fuel consumption benefit over the corresponding conventional vehicle.

\section{OPTIMIZATION WITH STATE CONSTRAINTS}

The general optimization problem defined in Section 2 does include state constraints but, in fact, the application of PMP presented generates the optimal solution only when these
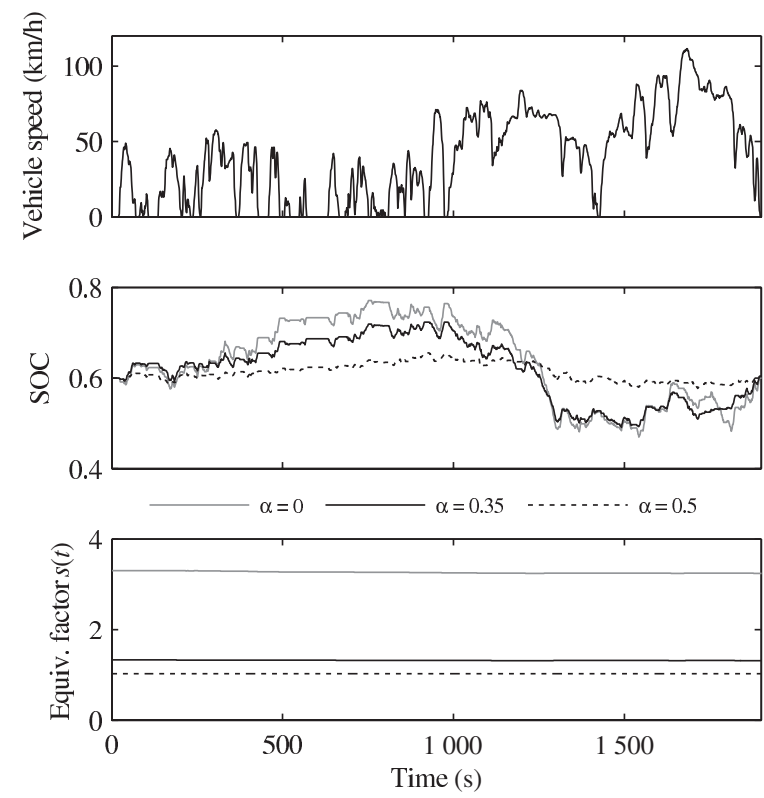

Figure 5

Example of optimization including battery aging: SOC evolution during a driving cycle (Artemis urban + suburban).
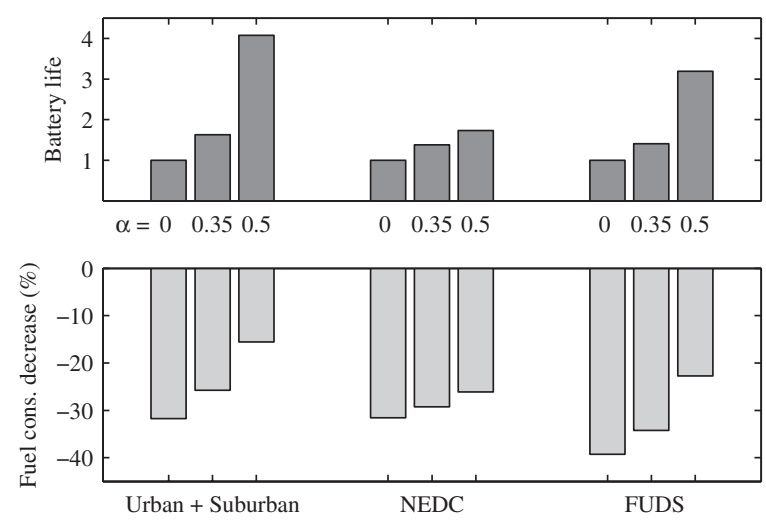

Figure 6

Trade-off between fuel consumption and battery aging. Fuel consumption is expressed as the reduction with respect to the conventional vehicle, and battery aging is represented by total projected battery life, relative to the standard ECMS case.

constraints are not actually reached. In practical implementations, there are normally methods to avoid overcoming the constraints but the resulting solution is suboptimal. Rigorous application of PMP in presence of state constraints (following, for example, the methods outlined in [21]) would be necessary but its online implementation represents still an open issue. The problem is not particularly relevant for regular HEV optimization, when the boundary values of SOC are rarely met in normal conditions; however, it becomes important in some special cases, for example when supercapacitors are present. With lower energy and higher power than a battery, supercapacitors can be completely charged and discharged very rapidly, thus 
their SOC is often hitting the allowable limits. One example of critical application is energy management strategies in a dual storage hybrid vehicle, with batteries and supercapacitors together. This problem is tackled in [22]: in order to overcome the numerical issues and general difficulty in online implementation, an heuristic control strategy is proposed for the online implementation, while the offline optimum is provided by dynamic programming. Current work is ongoing to allow for a practical implementation of PMP in these cases where the boundary limits are hit frequently.

\section{ECMS WITH ADDITIONAL STATE VARIABLES}

In some cases, the basic model that only includes SOC as system dynamic state is not sufficient. For example, in both the problems proposed in Sections 4.1 and 4.2, the cost should actually depend strongly on a temperature value (in the combustion chamber for $\mathrm{NO}_{x}$ emissions, of the battery for its aging). The assumption of constant temperature is therefore not meaningful, as it introduces an excessive simplification that reduces the significance of the problem. Both problems can reformulated to include the respective temperature states, as shown in this section. Additional state variables are also needed in order to include catalyst efficiency (which depends on temperature) [23,24], recuperation devices (thermoelectrical or thermodynamic systems using the exhaust heat [24]) or even the dynamics of SOC estimation error [25].

\subsection{Engine Temperature}

Consider the case in which basic fuel consumption reduction is the minimization objective during a cold-start operation. Using the standard ECMS with the hypothesis of constant temperature may lead to a suboptimal result, because the ECMS ignores the effect of temperature on the fuel consumption map during the warm-up phase. On the other hand, an heuristic strategy, being less sensitive to the engine model, is not impacted too much.

In order to account for the temperature effect on the engine fuel consumption, the thermal dynamics of the engine can be represented by a lumped-parameter model as follows $[24,26]$ :

$$
C_{e} \dot{\theta}_{e}=P_{t h, e}\left(T_{e}, \omega_{e}, \theta_{e}\right)-G_{e} \cdot\left(\theta_{e}-\theta_{0}\right)-P_{t h, a u x}
$$

where $T_{e}$ is the engine torque, $\omega_{e}$ its speed, $\theta_{e}$ the engine temperature, $C_{e}$ the engine equivalent thermal capacity, $G_{e}$ its equivalent thermal conductivity, $P_{t h, e}$ the sum of the friction power dissipated into heat and thermal power transferred from the engine exhaust gas to the coolant, $P_{\text {th,aux }}$ the thermal power drained by the cabin heater.

\subsubsection{Problem Definition}

The cost function remains the same as the standard problem, i.e. minimizing Equation (8). The difference is that the state vector $x$ now has two components, i.e. SOC and engine temperature:

$$
x=\left\{\xi, \theta_{e}\right\}
$$

The dynamic equations are respectively (6) and (28), and the fuel consumption that appears in the cost (7) is now a function of temperature as well as power split:

$$
\dot{m}_{f}=\dot{m}_{f}\left(u, \theta_{e}\right)
$$

\subsubsection{Solution}

The Hamiltonian is:

$$
H(\cdot)=P_{f u e l}\left(u, \theta_{e}, t\right)-\lambda_{1}(t) \cdot \dot{\xi}\left(u, \xi, \theta_{e}\right)-\lambda_{2}(t) \cdot \dot{\theta}_{e}\left(u, \theta_{e}, t\right)
$$

The SOC co-state $\lambda_{1}(t)$ is modified like in the standard case:

$$
\lambda_{1}(t)=-E_{\text {batt }} \cdot s(t)
$$

and the engine temperature co-state is written as:

$$
\lambda_{2}=-C_{e} \cdot p(t)
$$

so that each term in the Hamiltonian can be expressed with the physical units of power:

$$
H(\cdot)=P_{f u e l}\left(u, \theta_{e}, t\right)+s(t) P_{e c h}\left(u, \xi, \theta_{e}\right)+p(t) P_{t h, e}\left(u, \theta_{e}, t\right)
$$

where $P_{t h, e}=C_{e} \cdot \dot{\theta}_{e}$ is the power associated to the engine thermal exchange.

The variation of the equivalence factor $s(t)$ and the "temperature variation factor" $p(t)$ is computed according to Equation (5):

$$
\begin{gathered}
\dot{s}(t)=-s(t) \cdot \frac{\partial P_{e c h}\left(u, \xi, \theta_{e}, t\right)}{\partial \xi} \approx 0 \\
\dot{p}(t)=-\frac{\partial H\left(u, \xi, \theta_{e}, t\right)}{\partial \theta_{e}}=-\left(\frac{\partial P_{f u e l}}{\partial \theta_{e}}+p(t) \cdot \frac{\partial P_{t h, e}}{\partial \theta_{e}}\right)
\end{gathered}
$$

The variation of $s(t)$ is approximately zero as in the standard case (its expression not being affected by the additional state variable), while the variation of $p(t)$ cannot be neglected a priori.

\subsubsection{Results}

An example of application is shown in Figure 7, which shows simulation results comparing an heuristic strategy to the standard ECMS of Section 2 and the 2-state ECMS described by Equation (33). The fuel consumption is $4.89 \mathrm{~L} / 100 \mathrm{~km}$ for the heuristic strategy, $5.10 \mathrm{~L} / 100 \mathrm{~km}$ for the standard ECMS, and 4.67 for the 2-state ECMS: the standard ECMS, neglecting the temperature variation, is 

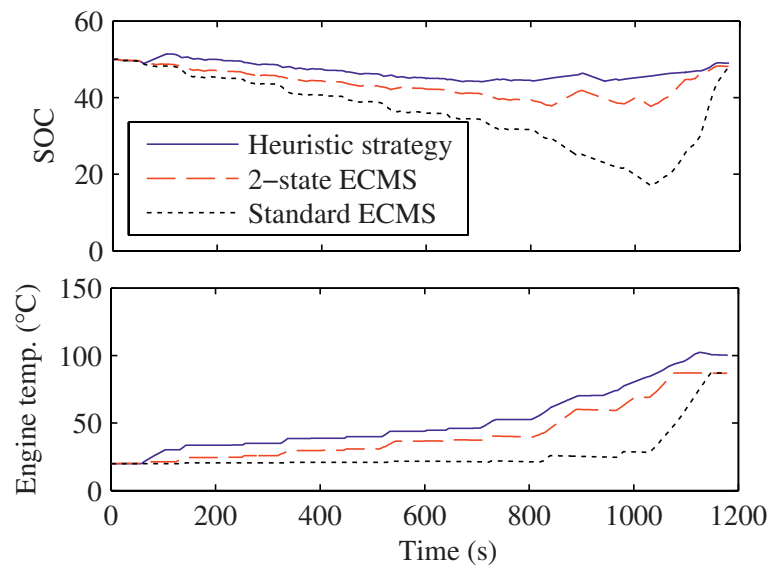

Figure 7

Optimization results on NEDC with cold start [26].

worse than the heuristic strategy. This is understandable by looking at the engine temperature, which rises very slowly with the standard ECMS, thus making the engine operate in cold condition (low efficiency) for a longer time. On the other hand, the 2-state ECMS that accounts for the temperature variation is more efficient than both the standard ECMS and the heuristic strategy, as expected.

\subsection{Engine and Catalyst Temperature}

If emissions are also to be optimized, the problem must be further modified in both the cost function and the system model, introducing engine temperature $\theta_{e}$ and catalyst temperature $\theta_{c}$, since both have an effect on the emission rates.

\subsubsection{Problem Definition}

The problem definition consists in the minimization of fuel consumption and emission rates, and is similar to the one introduced in Section 4.1:

$$
\begin{aligned}
L\left(\theta_{e}, \theta_{c}, u, t\right)= & Q_{l h v} \cdot\left[\left(1-\sum_{j} \alpha_{j}\right) \cdot \dot{m}_{f}\left(u, \theta_{e}, t\right)\right. \\
& \left.+\sum_{j} \alpha_{j} \cdot \dot{m}_{j}\left(u, \theta_{e}, \theta_{c}, t\right)\right]
\end{aligned}
$$

with $j=\left\{\mathrm{CO}, \mathrm{HC}, \mathrm{NO}_{x}\right\}$. Since the effect of temperature on the catalyst conversion efficiency is the same for the three pollutant emissions (at least in the simplified model considered here), the values $\alpha_{\mathrm{CO}}=\alpha_{3} \neq 0, \alpha_{\mathrm{NO}_{x}}=0, \alpha_{\mathrm{HC}}=0$ are used for simplicity.

\subsubsection{Solution}

The system has three dynamic states: $\theta_{e}, \theta_{c}, \xi$. Following the same approach as in Section 6.1, the Hamiltonian is:

$$
\begin{aligned}
H(\cdot)= & \left(1-\alpha_{3}\right) \cdot P_{f u e l}\left(u, \theta_{e}, t\right)+\alpha_{3} \cdot P_{\mathrm{CO}}\left(u, \theta_{e}, \theta_{c}, t\right) \\
& +s(t) \cdot P_{e c h}\left(u, \xi, \theta_{e}, t\right)+p(t) \cdot P_{t h, e}\left(u, \theta_{e}, t\right) \\
& +q(t) \cdot P_{t h, c}\left(u, \theta_{e}, \theta_{c}, t\right)
\end{aligned}
$$

where $P_{\mathrm{CO}}(\cdot) \triangleq Q_{l h v} \dot{m}_{\mathrm{CO}}$, and $P_{t h, c} \triangleq-C_{c} \dot{\theta}_{c}$ is the thermal power associated with the catalytic converter.

The Euler-Lagrange equations are:

$$
\begin{aligned}
\dot{s}(t)= & -s(t) \cdot \frac{\partial P_{e c h}\left(u, \xi, \theta_{e}, t\right)}{\partial \xi} \approx 0 \\
\dot{p}(t)= & -\frac{\partial H\left(u, \xi, \theta_{e}, \theta_{c}, t\right)}{\partial \theta_{e}} \\
= & -\left[\left(1-\alpha_{3}\right) \frac{\partial P_{f u e l}}{\partial \theta_{e}}+\alpha_{3} \frac{\partial P_{\mathrm{CO}}}{\partial \theta_{e}}\right. \\
& \left.+p(t) \frac{\partial P_{t h, e}}{\partial \theta_{e}}+q(t) \frac{\partial P_{t h, c}}{\partial \theta_{e}}\right] \\
\dot{q}(t)= & -\frac{\partial H\left(u, \xi, \theta_{e}, \theta_{c}, t\right)}{\partial \theta_{e c}} \\
= & -\left(\alpha_{3} \frac{\partial P_{\mathrm{CO}}}{\partial \theta_{c}}+q(t) \frac{\partial P_{t h, c}}{\partial \theta_{c}}\right)
\end{aligned}
$$

Note that the approach of [3] reduces to an approximation of this solution with $p \equiv 0, q \equiv 0$, while $\alpha_{3}$ (denoted as $\beta_{3}$ in that paper) varies to achieve different compromises between the cost and emissions. On the other hand, the strategy proposed in [8] is equivalent to this when $\alpha_{3}=1$ and $p \equiv 0$ (no engine thermal dynamics) but $q(t) \neq 0$.

\subsubsection{Results}

The presence of three co-states, two of which vary with coupled dynamics, poses a significant challenge for the numerical solution of the problem. Preliminary simulation results [24] are shown in Figure 8. These are obtained by manual search of the initial values $s(0), p(0), q(0)$ that satisfy all terminal constraints; the cost function is defined with

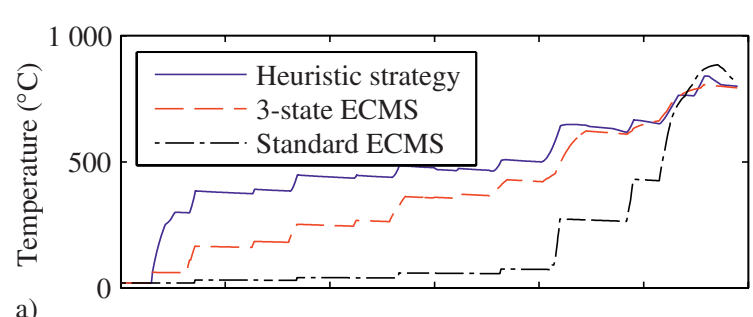

a)

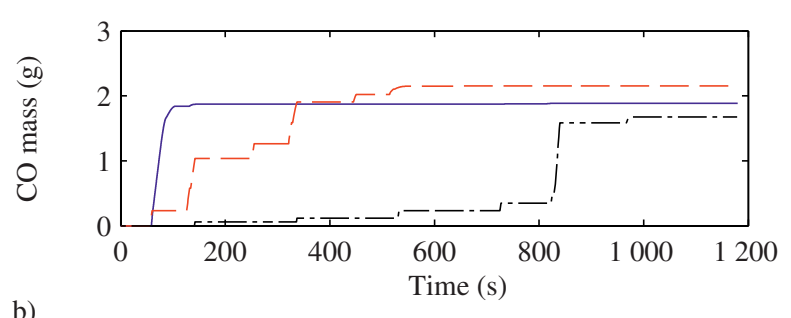

b)

Figure 8

Comparison of three strategies on the NEDC. a) Catalyst temperature, b) cumulative $\mathrm{CO}$ emission. Phases with $\mathrm{CO}$ increase or temperature rise correspond to engine-on phases, while temperature decrease or zero $\mathrm{CO}$ emission characterize engine-off phases [24]. 
$\alpha_{3}=0.25$. The total cost with the baseline heuristic strategy is 12.87 MJ. Despite its neglection of relevant dynamics, standard ECMS (Sect. 2) is already capable of attaining a similar result: $1.67 \mathrm{~g}$ of CO and $4.87 \mathrm{~L} / 100 \mathrm{~km}$ of fuel, with a cost function of $12.83 \mathrm{MJ}$. This result is obtained by limiting the engine-on phases and concentrating them toward the end of the cycle, rather than the fastening the rise of catalyst temperature, since standard ECMS is not temperaturesensitive. A better result is obtained with the full strategy (3-state ECMS): $2.15 \mathrm{~g} \mathrm{CO}$ and $4.78 \mathrm{~L} / 100 \mathrm{~km}$ of fuel, for a cost function of $12.58 \mathrm{MJ}$. The rise of temperature is faster than with the standard ECMS but less aggressive than with the heuristic strategy. See [24] for more detailed discussion of thermal optimization.

\subsection{Battery Temperature}

The battery characteristics, especially the internal resistance and aging effects, depend strongly on the temperature. While in most cases its effect is neglected, assuming that the cooling system keeps the battery pack at a constant and homogeneous temperature, it is also possible to modify the problem formulation and system model in order to account explicitly for the battery thermal dynamics, which have characteristic times comparable to SOC dynamics. For a simpler implementation, it is also possible to account for the temperature effect in the parameters, without explicitly including it in the problem formulation. In this section, the formulation of ECMS with battery aging of Section 4.2 is expanded to include the thermal dynamics. The thermal model presented in [27] is used:

$$
\begin{aligned}
\dot{\theta}_{b}= & \frac{1}{m c_{p}}\left(R_{t o t}\left(\xi, \theta_{b}, I_{b}\right) \cdot I_{b}^{2}\right. \\
& \left.+w_{t h}(\xi) \cdot I_{b} \cdot \theta_{b}-q_{n}\left(\theta_{b}\right)-q_{f}\left(u_{c}\right)\right)
\end{aligned}
$$

where $\theta_{b}$ represents the battery temperature, $m c_{p}$ is its thermal capacity, $R_{\text {tot }}$ the equivalent internal resistance, $I_{b}$ the total current, $w_{t h}(\xi)$ represents the entropic term that determines the reversible heat generation at the electrodes (due to the electrochemical reactions), $q_{n}\left(\theta_{b}\right)$ is the heat exhanged with the environment and $q_{f}\left(u_{c}\right)$ is the heat removed by the forced cooling system ( $u_{c}$ being its control variable).

\subsubsection{Problem Definition}

The system state is described by the SOC and the battery temperature, i.e. $x=\left\{\xi, \theta_{b}\right\}$. The cost function accounts for fuel consumption and battery aging, as in Section 4.2, but now the aging function - like the other battery parameters depends explicitly on the temperature:

$$
\begin{aligned}
L\left(\xi, \theta_{b}, u, u_{c}, t\right)= & \left(1-\alpha_{2}\right) P_{\text {fuel }}\left(u, u_{c}, t\right) \\
& +\alpha_{2} c_{a} \frac{\sigma\left(\xi, \theta_{b}, I_{b}\right)\left|I_{b}\left(\xi, \theta_{b}, u, u_{c}, t\right)\right|}{\Gamma}
\end{aligned}
$$

The control variables include the power split $u$ and the battery forced cooling $u_{c}$, since the objective is to integrate the thermal management in the overall optimization.

\subsubsection{Solution}

The Hamiltonian is given by:

$$
\begin{aligned}
H\left(\xi, \theta_{b}, u, u_{c}, t\right)= & \left(1-\alpha_{2}\right) P_{\text {fuel }}\left(u, u_{c}, t\right) \\
& +\alpha_{2} c_{a} \frac{\sigma\left(\xi, u, \theta_{b}\right)\left|I_{b}\left(\xi, \theta_{b}, u, u_{c}, t\right)\right|}{\Gamma} \\
& +s(t) \cdot P_{e c h}\left(\xi, \theta_{b}, u, u_{c}, t\right) \\
& +r(t) \cdot m c_{p} \dot{\theta}_{b}\left(\xi, \theta_{b}, u, u_{c}\right)
\end{aligned}
$$

where $r(t)$ is a non-dimensional factor proportional to the temperature co-state (which is $r(t) \cdot m c_{p}$ ). The two factors $s(t)$ and $r(t)$ in the Hamiltonian evolve according to their respective dynamic equations:

$$
\begin{aligned}
& \dot{s}(t)=-\frac{\partial H\left(\xi, \theta_{b}, u, u_{c}, t\right)}{\partial \xi} \\
& \dot{r}(t)=-\frac{\partial H\left(\xi, \theta_{b}, u, u_{c}, t\right)}{\partial \theta_{b}}
\end{aligned}
$$

The initial value of both $s(t)$ and $r(t)$ must be found in such a way that the terminal condition on SOC is met, and that the battery temperature remains within an acceptable range. Once again, the main difficulty is the numerical identification of these initial conditions, which is object of current investigation.

\section{CONCLUSION}

This paper presents some of the topics on which researchers are currently working at IFP Energies nouvelles. The common theme is the application of optimal control technique to cases more and more complete and complex but which all can be cast into an optimization problem to be solved using Pontryagin's Minimum Principle (PMP). Some applications, consisting in additional cost terms (such as emissions or battery aging, both computed using static maps), are almost immediate and yield good results. More interesting cases include system models with additional states, such as engine and catalyst temperature or battery temperature. For these cases, the basis of the analytical solution is provided in this paper but implementing the resulting strategy is quite difficult offline and impossible online, for the lack of robust adaptation methods for the optimization parameters (co-states). Current and future work is aimed at overcoming these numerical difficulties, either by appropriate algorithms or with alternative methods such as heuristics strategies to simplify the co-state estimation.

\section{REFERENCES}

1 Sciarretta A., Guzzella L. (2007) Control of hybrid electric vehicles, IEEE Control Syst. Mag. 27, 2, 60-70.

2 Chasse A., Hafidi G., Pognant-Gros P., Sciarretta A. (2009) Supervisory control of hybrid powertrains: an experimental benchmark of offline optimization and online energy management, Proceeding of the 2009 IFAC Workshop on Engine and Powertrain Control, Simulation and Modeling (E-COSM 2009), IFP, 3 Nov.-2 Dec., and Control Engineering Practice. 
3 Kessels J.T.B.A., Willems F.P.T., Schoot W.J., Van den Bosch P.P.J. (2010) Integrated energy and emission management for hybrid electric truck with scr aftertreatment, Proceedings of IEEE Vehicle Power and Propulsion Conference (VPPC, 2012), Lille, France, 1-3 Sept.

4 Serrao L., Onori S., Rizzoni G. (2009) ECMS as a Realization of Pontryagin's Minimum Principle for HEV Control, Proceedings of the 2009 American Control Conference (ACC 2009), St. Louis, Missouri, USA, 10-12 June.

5 Serrao L., Onori S., Rizzoni G. (2011) A comparative analysis of energy management strategies for hybrid electric vehicles, J. Dyn. Syst. Meas. Control 133, 3.

6 Kim N., Cha S., Peng H. (2011) Optimal control of hybrid electric vehicles based on Pontryagin's Minimum Principle, IEEE Trans. Control Syst. Technol. 19, 5, 1279-1287.

7 Chasse A., Pognant-Gros P., Sciarretta A. (2009) Online implementation of an optimal supervisory control for a parallel hybrid powertrain, SAE Int. J. Engines 2, 1, 1630-1638, SAE Paper 2009-01-1868.

8 Chasse A., Corde G., Del Mastro A., Perez F. (2010) HyHIL: online optimal control of a parallel hybrid with after-treatment constraint integration, Proceedings of 2010 IEEE Vehicle Power and Propulsion Conference (VPPC 2010), Lille, France, 1-3 Sept.

9 Kessels J.T.B.A., Koot M.W.T., van den Bosch P.P.J., Kok D.B. (2008) Online energy management for hybrid electric vehicles, IEEE Trans. Vehic. Technol. 57, 6, 3428-3440, ISSN 00189545. doi: 10.1109/TVT.2008.919988.

10 Musardo C., Staccia B., Bittanti S., Guezennec Y., Guzzella L., Rizzoni G. (2004) An adaptive algorithm for hybrid electric vehicles energy management, Proceedings of the Fisita 2004 World Automotive Congress, Barcelone, 23-27 May.

$11 \mathrm{Gu}$ B., Rizzoni G. (2006) An adaptive algorithm for hybrid electric vehicle energy management based on driving pattern recognition, Proceedings of the ASME 2006 International Mechanical Engineering Congress and Exposition (IMEC 2006), Chicago, IL, USA, 5-10 Nov.

12 Onori S., Serrao L., Rizzoni G. (2010) Adaptive equivalent consumption minimization strategy for hybrid electric vehicles, Proceedings of the ASME 2010 Dynamic Systems and Control Conference (DSCC 2010), Cambridge, Massachusetts, USA, 12-15 Sept.

13 Stockar S., Marano V., Rizzoni G., Guzzella L. (2010) Optimal control for plug-in hybrid electric vehicle applications, American Control Conference (ACC 2010), pp. 5024-5030. IEEE.

14 Tulpule P., Marano V., Rizzoni G. (2010) Energy management for plug-in hybrid electric vehicles using equivalent consumption minimisation strategy, Int. J. Electric Hybrid Vehicles 2, 4, 329-350.

15 Falières Q., Grasset O., Roblet K., Xu Y., Noiret C., Serrao L., Sciarretta A. (2011) A contradictory analysis of GM Voltecpowertrain, Proceedings of the European Electric Vehicle Conference (EEVC 2011), Bruxelles, 26-28 Oct.
16 Grebe U.D., Nitz L.T. (2011) Voltec - the propulsion system for Chevrolet Volt and Opel Ampera, ATZ autotechnology Edition, 2011-02.

17 Miller M.A., Holmes A.G., Conlon B.M., Savagian P.J. (2011) The GM Voltec 4ET50 multi-mode electric transaxle, SAE Int. J. Engines 4, 1, 1102.

18 Ao G.Q., Qiang J.X., Zhong H., Mao X.J., Yang L., Zhuo B. (2008) Fuel economy and $\mathrm{NO}_{x}$ emission potential investigation and trade-off of a hybrid electric vehicle based on dynamic programming, Proc. IMechE, Part D: J. Automobile Engineering 222, 10, 1851-1864.

19 Grondin O., Thibault L., Moulin Ph., Chasse A., Sciarretta A. (2011) Energy management strategy for Diesel hybrid electric vehicle, Proceedings of 7th IEEE Vehicle Power and Propulsion Conference (VPPC 2011), Chicago, Il, USA, 6-9 Sept.

20 Serrao L., Onori S., Sciarretta A., Guezennec Y., Rizzoni G. (2011) Optimal energy management of hybrid electric vehicles including battery aging, Proceedings of the 2011 American Control Conference.

21 Geering H.P. (2007) Optimal Control with Engineering Applications, Springer, Berlin, Heidelberg.

22 Malaizé J., Tona P. (2011) Optimization-based control design for hybrid energy storage systems in electric vehicles, Proceedings of 7th IEEE Vehicle Power and Propulsion Conference (VPPC 2011), Chicago, Il, USA, 6-9 Sept.

23 Cloudt R., Willems F. (2011) Integrated emission management strategy for cost-optimal engine-aftertreatment operation, $S A E$ Int. J. Engines 4, 1, 1784.

24 Merz F., Sciarretta A., Labadie J.C., Serrao L. (2012) On the optimal thermal management of hybrid-electric vehicles with heat recovery systems, Oil Gas Sci. Technol. - Rev. IFP Energies nouvelles 67, 4, 601-612.

25 Larsson V., Johannesson L., Egardt B. (2011) Influence of state of charge estimation uncertainty on energy management strategies for hybrid electric vehicles, Proceedings of the 18th World Congress of the International Federation of Automatic Control (IFAC 2011), Milano, Italy, 28 Aug.-2 Sept.

26 Lescot J., Sciarretta A., Chamaillard Y., Charlet A. (2010) On the integration of optimal energy management and thermal management of hybrid electric vehicles, Proceedings of IEEE Vehicle Power and Propulsion Conference (VPPC 2010), Lille, France, 1-3 Sept.

27 Di Domenico D., Prada E., Creff Y. (2011) An adaptive strategy for Li-ion battery soc estimation, Proceedings of the 18th World Congress of the International Federation of Automatic Control (IFAC 2011), Milano, Italy, 28 Aug.-2 Sept.

Final manuscript received in October 2012 Published online in March 2013

Copyright $\odot 2013$ IFP Energies nouvelles

Permission to make digital or hard copies of part or all of this work for personal or classroom use is granted without fee provided that copies are not made or distributed for profit or commercial advantage and that copies bear this notice and the full citation on the first page. Copyrights for components of this work owned by others than IFP Energies nouvelles must be honored. Abstracting with credit is permitted. To copy otherwise, to republish, to post on servers, or to redistribute to lists, requires prior specific permission and/or a fee: Request permission from Information Mission, IFP Energies nouvelles, fax. +331475270 96, or revueogst@ifpen.fr. 